\title{
Clinical and haemodynamic effects of diazoxide in primary pulmonary hypertension
}

\author{
MICHAEL HONEY, LAWRENCE COTTER, NICHOLAS DAVIES, \\ AND DAVID DENISON
}

From the Department of Cardiology and the Respiratory Function Laboratory, Brompton Hospital, London

ABSTRACT Diazoxide was injected into the pulmonary artery in nine patients with primary
pulmonary hypertension. There was no significant change in pulmonary artery pressure, which fell
by more than $10 \mathrm{mmHg}$ in only two patients. The pulmonary blood flow increased in all patients
as a result of a fall in pulmonary vascular resistance (by 4 to 17 units). Systematic vascular resistance
also fell as expected in all patients. Oral diazoxide was given to seven patients, two of whom showed
sustained clinical improvement while remaining on treatment ( 400 to 600 mg daily). Five patients
were unable to tolerate the drug, because of nausea and sickness (two), peripheral oedema requiring
large doses of diuretics (four), diabetes (three), and postural hypotension (one). Hirsutes was
troublesome in the two patients remaining on treatment. Diazoxide may be useful in the management
of some patients with primary pulmonary hypertension, but its use is limited by the frequency of
side effects. Our results suggest that examination of other potent vasodilators may be worth while.

Diazoxide is a benzothiadiazine derivative related to the thiazide diuretics but without diuretic activity. ${ }^{1}$ It is a potent dilator of resistance vessels and has been widely used intravenously in the treatment of acute hypersensitive emergencies. ${ }^{2}$ Though it has been shown to be effective orally in the treatment of systemic hypertension, ${ }^{34}$ it was found to cause diabetes and for this reason never came into general use. There is no consistently effective treatment for primary pulmonary hypertension, but recently Wang et $a l^{5}$ have reported a reduction in pulmonary vascular resistance after injection of diazoxide, and clinical improvement in two out of three patients. After these observations, we have administered diazoxide to nine patients with primary pulmonary hypertension.

\section{Patients and methods}

Nine patients gave informed consent to taking part in the investigation. All were women, aged from 25 to 62 years. Seven were European (five British or Irish, one Icelandic); one was from Sri Lanka and one an Indian from East Africa, but in neither was there any evidence of filariasis. All had the clinical features of primary or un-

Address for reprint requests: Dr M Honey, Brompton Hospital, Fulham Road, London SW3 6HP. explained pulmonary hypertension. All nine patients had a diagnostic cardiac catheterisation, and pulmonary arteriograms were obtained in seven of these. In none was there any evidence of an underlying congenital cardiac lesion, pulmonary thromboembolism, or pulmonary veno-occlusive disease. One patient (case 6) had chronic partially reversible airways obstruction, but the disturbance of lung function was insufficient to account for severe pulmonary vascular disease. Three patients (cases 2,3 , and 5) have died and two were examined postmortem. In one of these (case 5) pulmonary function studies during life suggested that vascular obstruction was at capillary level, and necropsy examination did not show the plexogenic pulmonary arteriopathy characteristic of "classical primary pulmonary hypertension." In the other (case 2), the necropsy appearances were typical of primary pulmonary hypertension with plexiform and dilatation lesions but without necrotising arteritis.

PARENTERAL DIAZOXIDE STUDY

At cardiac catheterisation, a catheter was placed in the main pulmonary trunk for measurement of pulmonary artery pressure, blood sampling, and injection of diazoxide $\mathbf{A}$ second catheter was introduced into a systemic artery. Oxygen 
tension was determined using an automatic $\mathrm{pH}$ and blood gas electrode unit (Corning 165); oxygen content of pulmonary and systemic arterial blood was derived from the measured oxygen tension using oxygen dissociation curve data $^{67}$ with allowance for physically dissolved oxygen. Oxygen uptake was measured by the method of Davies and Denison ${ }^{8}$ which uses respiratory mass spectrometry alone. This technique allows minute ventilation and oxygen consumption to be monitored continuously throughout the study by remote means, so that slight changes in cardiac output may be measured accurately from direct Fick analyses. Pulmonary vascular resistance was calculated from pulmonary artery mean pressure, assumed or measured left atrial (or pulmonary artery wedge) mean pressure, and pulmonary blood flow.

Duplicate control measurements of pressures and cardiac output were made. Diazoxide was then injected into the pulmonary trunk in an initial dose of $45 \mathrm{mg}$; further doses were injected at four minute intervals to a maximum cumulative dose of 300 to $600 \mathrm{mg}$. Pulmonary and systemic arterial blood was sampled simultaneously over a one minute period four minutes after each injection and 12 minutes after the final dose. Metabolic gas exchange was measured in duplicate during each sampling period.

Table 1 shows the average of two control measurements. The data after parenteral diazoxide are those recorded at the time of maximum haemodynamic change, usually observed after the final dose of injected diazoxide or 12 minutes later.

The significance of changes in group means was assessed using the paired $t$ test.

LONG-TERM ORAL TREATMENT WITH DIAZOXIDE Oral diazoxide was then started in seven of the nine patients, the dose being increased progressively to the maximum tolerated (150 to $600 \mathrm{mg}$ daily). In five of the six survivors, cardiac catheterisation was repeated six to 12 weeks after the first study. Control measurements were made with the patient on the regular daily schedule of oral diazoxide. Diazoxide was then injected into the pulmonary artery in the same dose as at the pretreatment catheterisation, and measurements repeated.

\section{Results}

INITIAL PARENTERAL DIAZOXIDE STUDY

(TABLE 1, FIGS 1-3)

The pulmonary artery mean pressure fell by

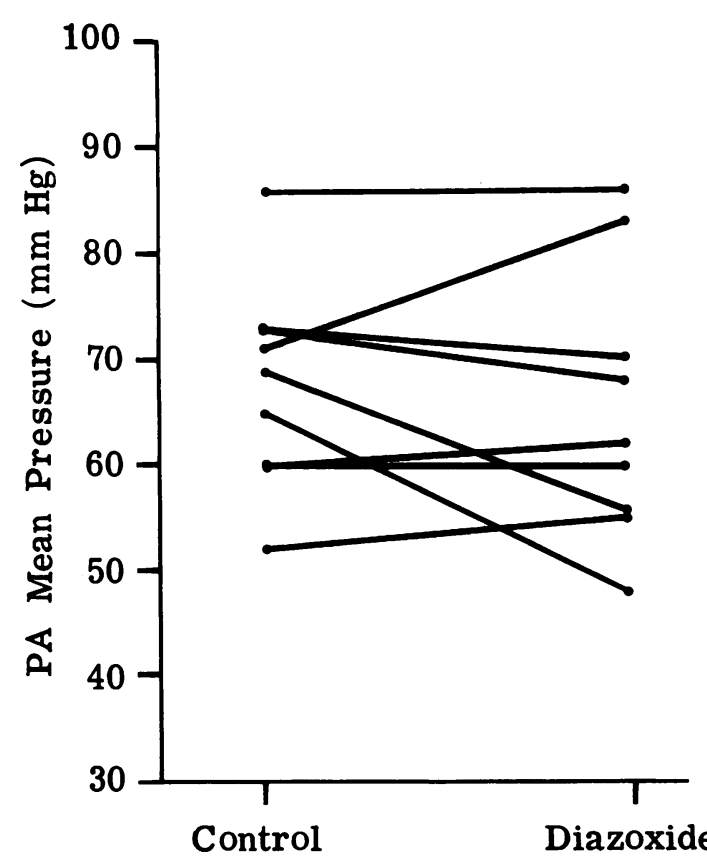

Fig 1 Effect of injected diazoxide on pulmonary artery mean pressure in nine patients.

more than $10 \mathrm{mmHg}$ in only two patients, changed by $5 \mathrm{mmHg}$ or less in six, and rose by $12 \mathrm{mmHg}$ in one patient. However, the pulmonary blood flow increased in every case, by 1.2 to $3.21 / \mathrm{min}$. Pulmonary blood flow increasedo from an average control level of $3.11 / \mathrm{min}$ to $x$ an average of $5.41 / \mathrm{min}(\mathrm{p}<0.001)$. The pul? monary vascular resistance likewise fell in every case by between 3.9 and 17.0 units, from average 20.7 to 11.6 units $(p<0.001)$. Con-o currently, systemic arterial mean blood pressure fell in every case from average $95 \mathrm{mmHg}(82$ to $123 \mathrm{mmHg}$ ) to average $70 \mathrm{mmHg}$ (51 to 86 . $\mathrm{mmHg}$ ), and total systemic resistance from 33 N units to 14 .

\section{EFFECTS OF ORAL DIAZOXIDE TREATMENT}

(TABLE 2)

In five patients, symptoms (exertional breathless $-\frac{0}{2}$ ness, syncope or near-syncope, and chest pain $)_{4}^{\Phi}$ were unimproved by diazoxide in the maximum tolerated dose. Further increase in dose was prohibited by serious side effects in all theseop cases. Nausea and sickness was severe in two and postural hypotension was severe in case $7, \frac{2}{2}$ who had shown the greatest fall in systemice blood pressure during the initial study. Three patients became diabetic; two in whom treat 


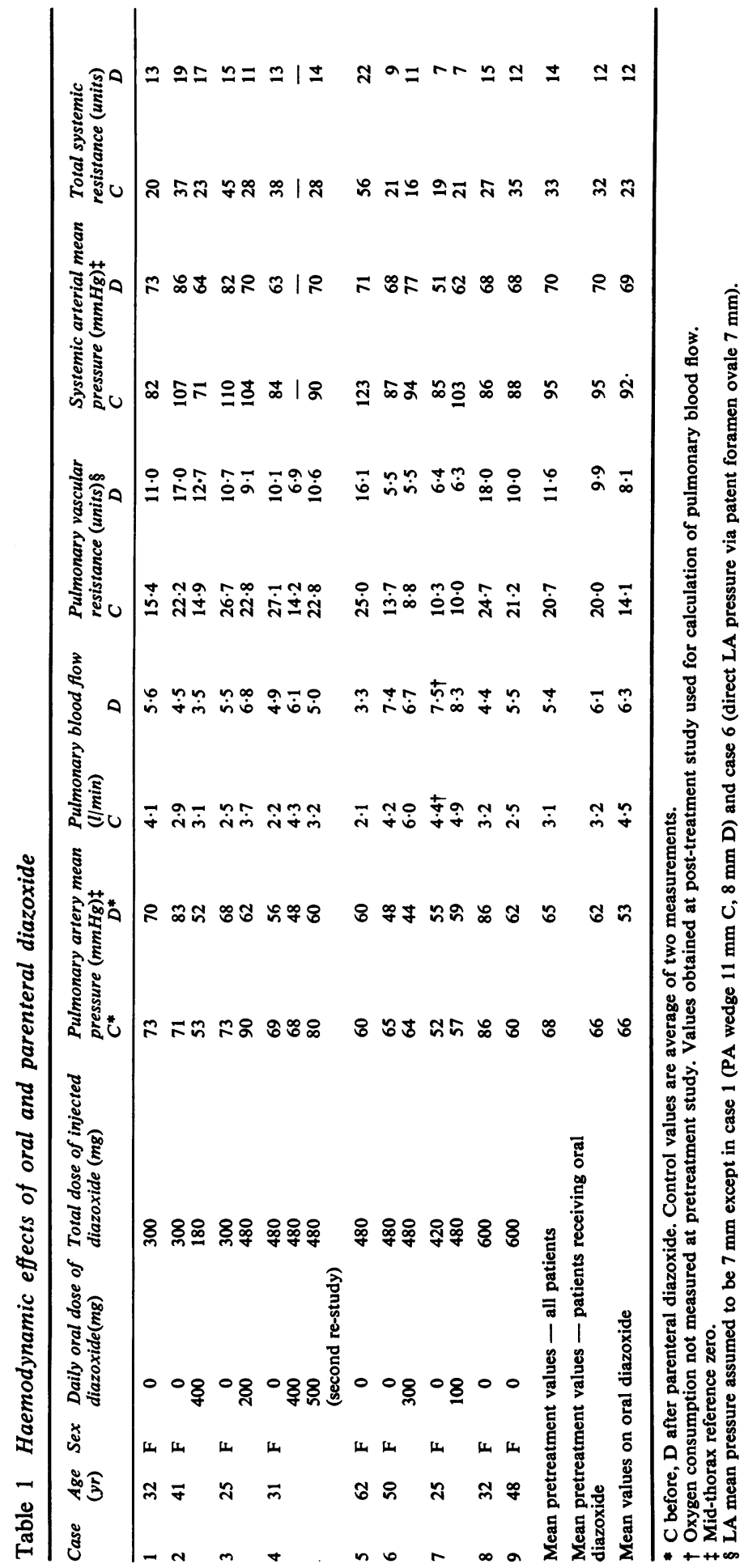




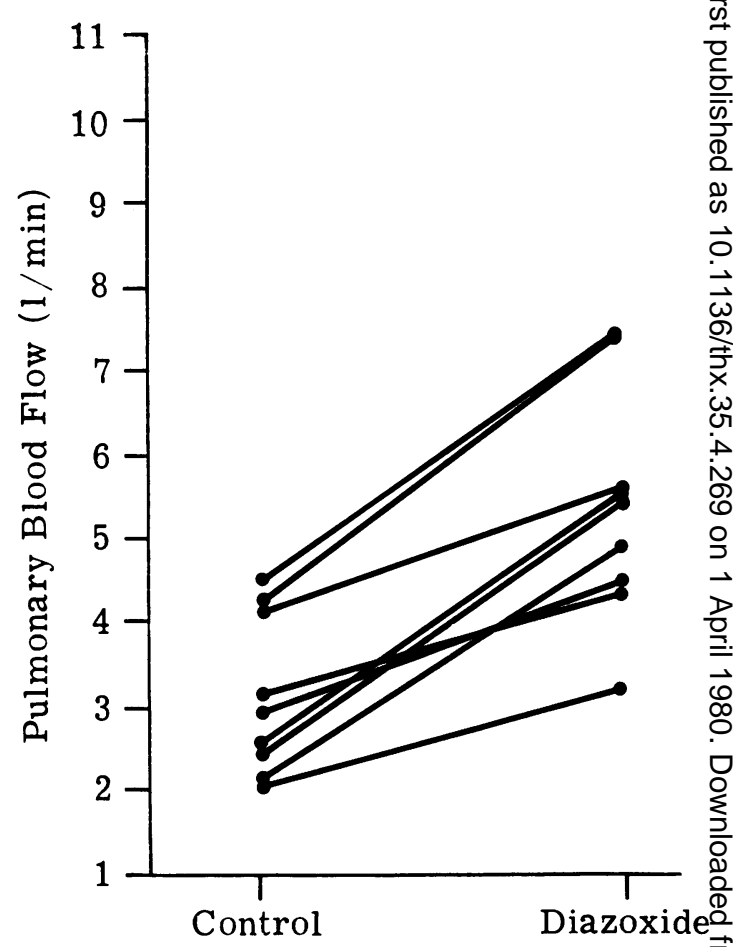

Fig 2 Effect of injected diazoxide on pulmonary blood flow in nine patients.

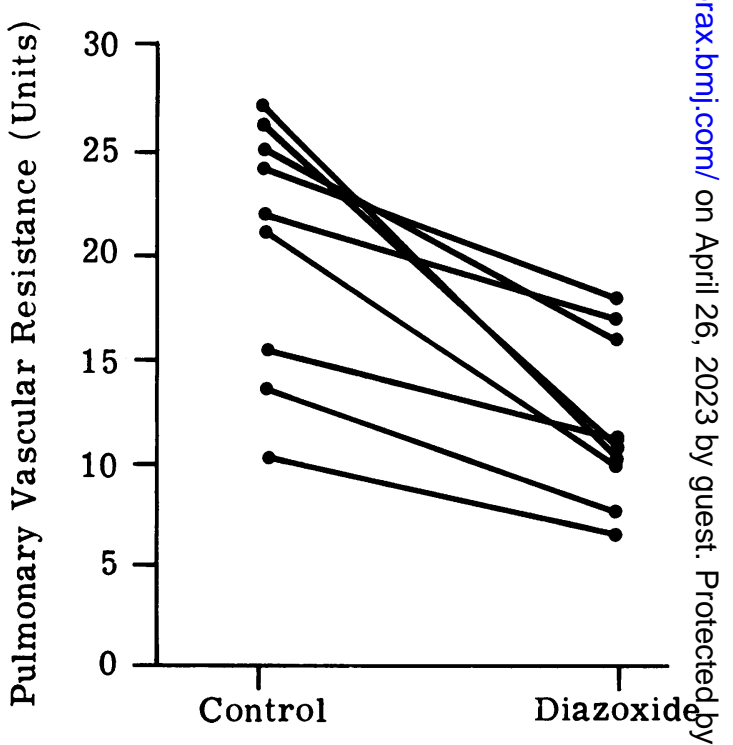

Fig 3 Effect of injected diazoxide on pulmonary vascular resistance in nine patients. 
ment was continued required insulin and glibenclamide for control of hyperglycaemia. Four patients developed signs of fluid retention; three required large doses of potent diuretics for control of oedema, and the other deteriorated progressively with signs of increasing heart failure. Diazoxide was eventually discontinued in all, and three of these four patients subsequently died, one (case 5) within three weeks of stopping treatment and the others (cases 2 and 3) 10 and 12 months later.

Two patients have improved, one dramatically. This young woman (case 4) from Sri Lanka was so severely disabled by breathlessness, chest pain, and syncope on the slightest exertion that lung transplantation was seriously considered. On treatment, there was a striking improvement in exercise tolerance: she was less breathless and no longer had syncope or chest pain on effort. She could walk one mile on the level and climb stairs, and married. At first, she attributed headache to the treatment, but the only definite side effect was a profuse growth of hair on the face and limbs, because of which she was unwilling to increase the dose above $300 \mathrm{mg}$ bd. The other patient (case 6) who improved was also treated with salbutamol, sodium cromoglycate, and beclomethasone inhalations, with some symptomatic and objective improvement in airways obstruction, before starting diazoxide treatment. Symptomatic improvement continued when diazoxide was started, but she has needed regular diuretic therapy to control fluid retention, particularly during exacerbations of bronchitis. She has also noticed increased growth of hair on the face and arms.

\section{REINVESTIGATION DURING ORAL DIAZOXIDE}

TREATMENT (TABLE 1, FIGS 4-6)

Pulmonary artery pressure before administration of parenteral diazoxide was unchanged from (or slightly higher than) control pulmonary artery pressure in the pretreatment study in four of the five patients. In three of these four patients, pulmonary artery pressure on oral diazoxide was higher than after parenteral diazoxide in the pretreatment study. In all these three, there was a conspicuous fall in pulmonary artery pressure with parenteral diazoxide ( 20 to $28 \mathrm{mmHg}$ ), greater in each case than the fall in pulmonary artery pressure with parenteral diazoxide before starting oral treatment. In one patient (case 2) pulmonary artery pressure was lower on oral diazoxide than in the pretreatment study, either before or after parenteral diazoxide. In another patient (case 7), pulmonary artery pressure was unaffected by the small dose of oral diazoxide or by the drug given parenterally in either study.

Pulmonary blood flow on oral diazoxide was higher than before treatment in all five cases, though the change was small in two (range 0.2

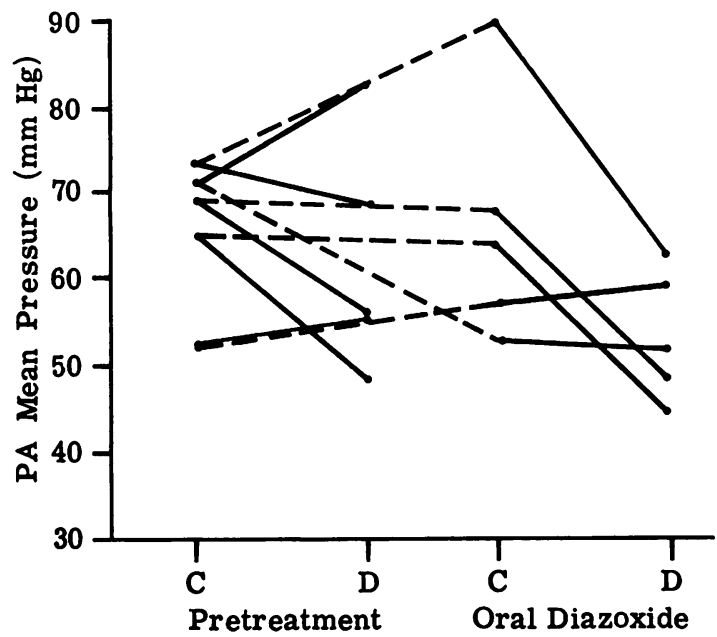

Fig 4 Effects of oral and injected diazoxide on pulmonary artery mean pressure in five recatheterised patients treated with oral diazoxide. Continuous lines indicate effect of injected diazoxide, both before and during oral treatment. Broken lines indicate effect of oral diazoxide on $P A$ mean pressure before injection of diazoxide. $C=$ before, $D=$ after injection of diazoxide.

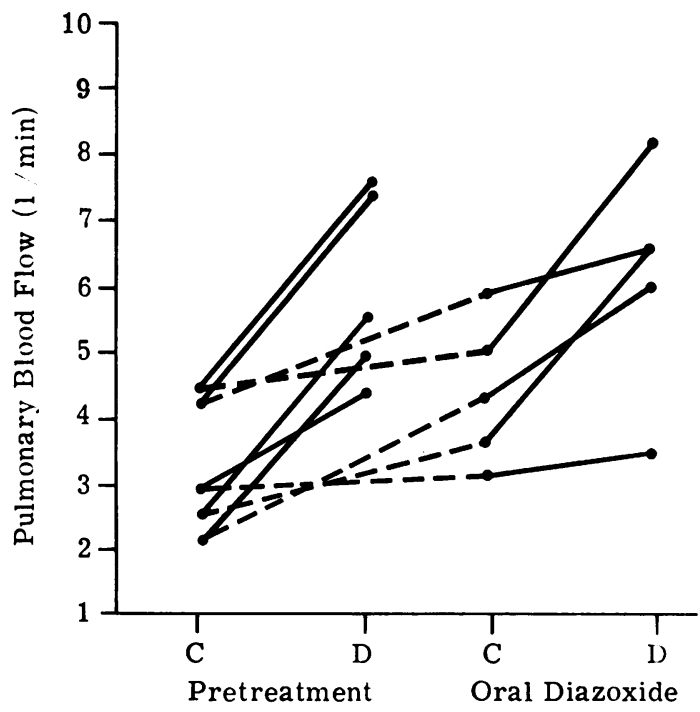

Fig 5 Effects of oral and injected diazoxide on pulmonary blood flow in five patients treated with oral diazoxide. 


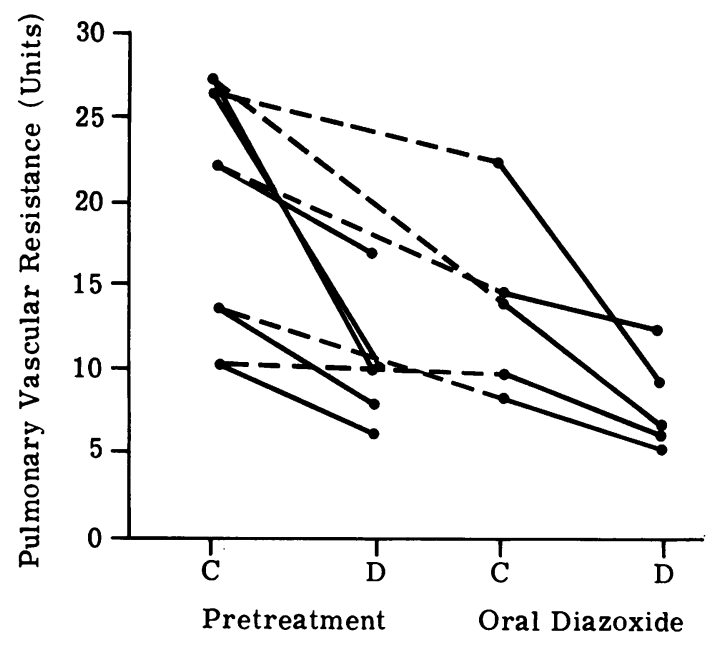

Fig 6 Effects of oral and injected diazoxide on pulmonary vascular resistance in five patients treated with oral diazoxide.

to $2 \cdot 11 / \mathrm{min}$ ), the average value rising from $3 \cdot 2$ to $4.51 / \mathrm{min}$. There was, however, a further increase in pulmonary blood flow $(0.4$ to 3.1 $1 / \mathrm{min}$ ) after parenteral diazoxide, the average value rising to $6 \cdot 31 / \mathrm{min}$.

Likewise, pulmonary vascular resistance was lower than before treatment in four of the five patients, the fall ranging from 3.9 to 12.9 units. In the other patient, who could tolerate only a small dose (50 $\mathrm{mg}$ bd), there was no change. In all five cases, there was a further fall in pulmonary vascular resistance with parenteral diazoxide.

One patient (case 4) had a second re-study while continuing oral diazoxide treatment. On this occasion, the fall in pulmonary vascular resistance was less than at the first re-study; it is perhaps relevant that on this occasion the dose of oral diazoxide was omitted on the morning of investigation.

\section{Discussion}

Though acetylcholine injected directly into the pulmonary artery in patients with mitral stenosis or primary pulmonary hypertension causes a fall in pulmonary artery pressure and vascular resistance, ${ }^{9}$ this drug is ineffective when given orally. Intravenous isoprenaline causes active pulmonary vasodilation $^{10}$ and lowers pulmonary vascular resistance in mitral valve disease and in primary pulmonary hypertension; Shettigar et $a l^{11}$ found that sublingual isoprenaline given every two hours caused a sustained reduction in pulmonary? artery pressure and pulmonary vascular resist ance, and symptomatic improvement, in a patient? with primary pulmonary hypertension. Tolazoline an alpha-adrenergic antagonist, has been reporteक to reduce pulmonary artery pressure and vascular resistance in primary pulmonary hyper: tension $^{11} 12$ and in other forms of pulmonary hypertension, but there have been no reports of successful long-term treatment with oral tola $\vec{x}$ zoline. There is thus still a need for a potentw pulmonary vasodilator which is effective wherl given orally as well as parenterally and can bed given in adequate doses over a long periodo without side effects. Wang et $a l^{5}$ administerecB diazoxide parenterally and orally to three patients with primary pulmonary hypertension; all thre responded in the acute experiment, one im proved temporarily on oral treatment, and on $\overrightarrow{0}$ obtained symptomatic benefit lasting over period of nearly three years.

Our experience confirms that of Wang et al. There was no significant fall in pulmonary artery pressure after injection of diazoxide, though in two of the nine patients falls of 13 and $17 \mathrm{mmHg}$ were recorded. However, there was a significan? increase in pulmonary blood flow and a significane fall in pulmonary vascular resistance in the group? as a whole, though the magnitude of the change varied widely in the individual patients. Though we did not measure pulmonary blood volume $\vec{\sigma}$ we believe that the pulmonary vasodilatation resulting from diazoxide administration is an active process and not the passive consequence of an increase in pulmonary blood volume. ${ }^{13}$ Irn all our patients there was, as expected, a con국 current fall in systemic arterial pressure, an of the calculated fall in systemic resistance was greater than the fall in pulmonary resistance this would be expected to lead to a shift in blood from pulmonary to systemic vascular bed. $\widetilde{N}$

Despite these encouraging results, only one patient (case 4) showed impressive clinicaf benefit on oral treatment with diazoxide. One other patient (case 6 ) improved, but was also having treatment for chronic asthma. These two patients both showed substantial falls in pul monary vascular resistance not only with parenteral diazoxide, but also on oral treatment ${ }^{-}$ Other patients did not respond clinically, despitē comparable falls in pulmonary vascular resistance $\frac{\widehat{D}}{0}$ or pulmonary artery pressure.

Failure of the other patients to respond maye have resulted from their inability to take arf adequate dose of the drug. This suggestion 
received support from the observation that at the time of the haemodynamic study during continued oral treatment, parenteral diazoxide resulted in further increase in pulmonary blood flow and fall in pulmonary vascular resistance. Wang et $\mathrm{al}^{5}$ found that a dose of $600 \mathrm{mg}$ daily appeared to be necessary to maintain improvement and correlated this with blood levels exceeding $75 \mu \mathrm{g} / \mathrm{ml}$. We did not measure blood levels but found that only one of our patients was able to tolerate $600 \mathrm{mg}$ daily and most had serious side effects at doses of 150 to $400 \mathrm{mg}$ daily.

The relief of exertional syncope can readily be accounted for by the observed increase in cardiac output, resulting from a fall in pulmonary vascular resistance. It is less easy to explain the striking improvement in breathlessness observed by our most successful patient. The combined effect of a slight fall in pulmonary artery pressure and a large increase in pulmonary blood flow is a further increase in right ventricular work. For this reason, and because of the sodium and water retention diazoxide induces, it would not be unexpected if diazoxide therapy precipitated right heart failure in patients with primary pulmonary hypertension. In four of our patients, peripheral oedema appeared during treatment and required large doses of diuretics for its control.

In a disease with such a gloomy prognosis, it is a minor triumph if a new form of treatment can produce worthwhile and sustained improvement in even a small proportion of patients. In the combined experience of Wang et $a l^{5}$ and ourselves, two or three out of 12 patients had such a result, though even they still have severe pulmonary arterial hypertension. Our experience suggests that the search for a more effective and less toxic pulmonary vasodilator should be rewarding. Other vasodilators highly effective in the treatment of systemic hypertension appear worthy of study and in particular minoxidil has been shown to reduce pulmonary vascular resistance in the experimental animal. ${ }^{14}$ Lit 1 le is known of the pathogenesis of primary pulmonary hypertension, but it seems likely that an unknown agent or agents cause pulmonary vasoconstriction, possibly in the presence of some predisposing factor, before the development of irreversible organic changes in the pulmonary vasculature. ${ }^{15}$ Treatment with a pulmonary vasodilator at this stage might reverse the process, though this cannot be expected when the stage of progressive fibrous vascular occlusion with plexiform and dilatation lesions has been reached.
We are grateful to Professor Margaret TurnerWarwick, Dr J Batten, Dr DG Gibson and Dr RV Gibson for permission to report patients under their care, and to Dr S Banim, Dr SW Clarke, Dr M Erooga, Dr AJ Handley, Dr HM Leather, Dr K Palsson and Dr GC Sutton, for referring patients for investigation and treatment. We also thank Ms M Rehahn for statistical advice.

\section{References}

1 Koch-Weser J. Drug therapy. Diazoxide. $N$ Engl J Med 1976; 294:1271-4.

2 Moser M. Diazoxide - an effective vasodilator in accelerated hypertension. Am Heart J 1974; 87: 791-5.

3 Pohl JEF, Thurston $H$. Use of diazoxide in hypertension with renal failure. Br Med J 1971; 4:142-5.

4 Pohl JEF, Thurston H, Davis D, Morgan MY. Successful use of diazoxide in the treatment of severe toxaemia of pregnancy. Br Med J 1972; 2:568-70.

5 Wang SWS, Pohl JEF, Rowlands DJ, Wade EG. Diazoxide in treatment of primary pulmonary hypertension. Br Heart J 1978; 40:572-4.

6 Kelman GR. Digital computer subroutine for the conversion of oxygen tension into saturation. J Appl Physiol 1966; 21:1375-6.

7 Severinghaus JW. Blood gas calculator. J Appl Physiol 1966; 21:1108-16.

8 Davies NJH, Denison DM. The measurement of metabolic gas exchange and minute volume by mass spectrometry alone. Respir Physiol 1979; 36:261-7.

9 Wood P, Besterman EM, Towers MK, McIlroy MB. The effect of acetylcholine on pulmonary vascular resistance and left atrial pressure in mitral stenosis. Br Heart $J$ 1957; 19:279-86.

10 Schreiner BF, Murphy GW, James DH, Yu PN. Effects of isoproterenol on the pulmonary blood volume in patients with valvular heart disease and primary myocardial disease. Circulation 1968; 37:220-31.

11 Shettigar UR, Hultgren HN, Specter M, Martin R, Davies DH. Primary pulmonary hypertension: favorable effect of isoproterenol, $N$ Engl J Med 1976; 295:1414-5.

12 Dresdale DT, Michtom RJ, Schultz M. Recent studies in primary pulmonary hypertension including pharmacodynamic observations on pulmonary vascular resistance. Bull NY Acad Med 1954; 30:195-207.

13 Oakley CM, Glick G, Luria MN, Schreiner BF, $\mathrm{Yu}$ PN. Some regulatory mechanisms of the human pulmonary vascular bed. Circulation 1962; 26:917-30. 
14 Weir EK, Chidsey CA, Weil JV, Grover RF. 15 Heath D, Harris P. The human pulmonary $\frac{\overline{\bar{S}}}{\vec{D}}$ Minoxidil reduces pulmonary vascular resistance in dogs and cattle. $J$ Lab Clin Med 1976; 88: circulation. Second edition. Edinburgh: Churchill 885-94. Livingstone, 1977. 